\title{
Agôn
}

Revue des arts de la scène

Critiques | Saison 2010-2011

« 45. 232.511»: quand les chiffrent remplacent les êtres

Spectacle mis en scène par Ana Milena Navarro, présenté au théâtre Jorge Eliécer Gaitán à Bogotá

\section{Vivianne Reyne}

\section{OpenEdition}

Journals

Édition électronique

URL : http://journals.openedition.org/agon/1370

DOI : 10.4000/agon.1370

ISSN : 1961-8581

\section{Éditeur}

Association Agôn

\section{Référence électronique}

Vivianne Reyne, « « 45. 232. 511 » : quand les chiffrent remplacent les êtres », Agôn [En ligne], Critiques, mis en ligne le 09 février 2019, consulté le 23 septembre 2020. URL : http://journals.openedition.org/ agon/1370; DOI : https://doi.org/10.4000/agon.1370

Ce document a été généré automatiquement le 23 septembre 2020.

Association Agôn et les auteurs des articles 


\section{«45.232. $511 »:$ quand les chiffrent remplacent les êtres}

Spectacle mis en scène par Ana Milena Navarro, présenté au théâtre Jorge Eliécer Gaitán à Bogotá

\section{Vivianne Reyne}

Les chiffres jouent un rôle important en Colombie : nombre de morts, de blessés, de déplacés... mais aussi nombre de victimes et de bourreaux, nombre d'indifférents sans noms. Le conflit militaire et politique colombien, qui oppose, notamment et depuis plus de cinquante ans les Forces Armées Révolutionnaires de Colombie (FARC) et les paramilitaires, indirectement soutenus par le gouvernement, constitue une réalité étouffante mais propice à la créativité des artistes de ce pays. 
« 45.232.511 », mis en scène par Ana Milena Navarro

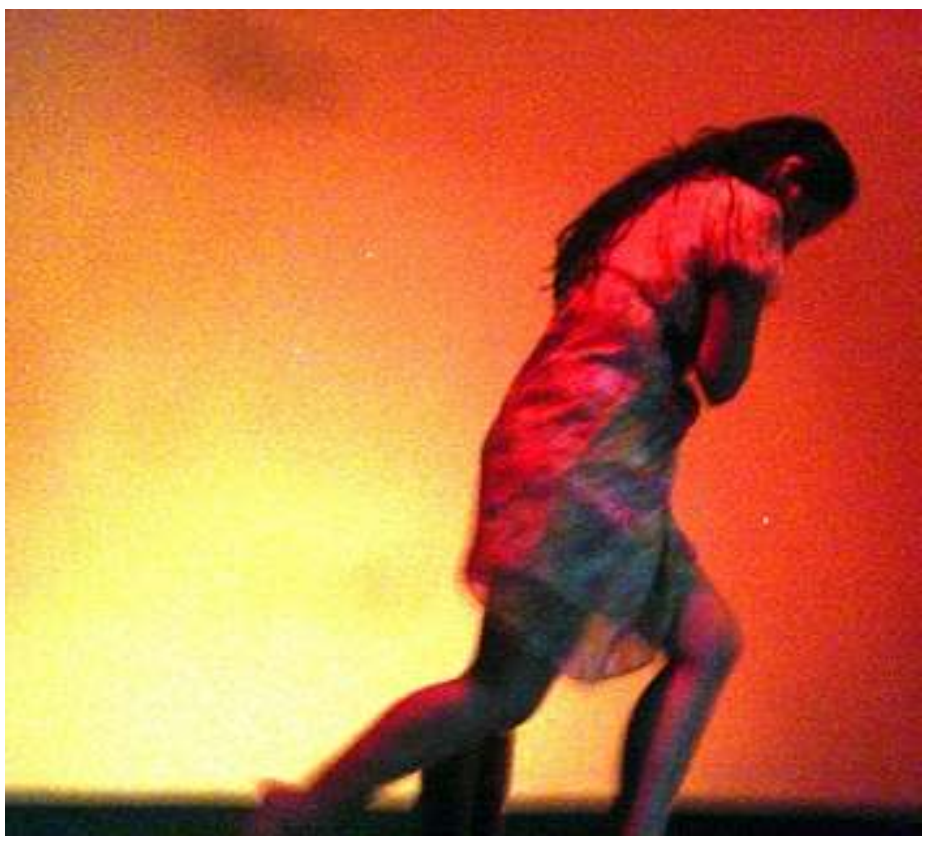

CRÉDIT : DR

2 Le spectacle mis en scène par Ana Milena Navarro, professeur de danse contemporaine à l'Université Jorge Tadeo Lozano de Bogotá, et qui sera représenté dans le célèbre théâtre Jorge Eliécer Gaitán d'ici à la fin de l'année 2010, est un brillant exemple de cette créativité, de l'expression esthétique et éthique, d'une société blessée. « 45. 232. 511 ", titre du spectacle, représente le nombre de Colombiens recensés jusqu'à ce jour : plus de quarante cinq millions de personnes qui connaissent la réalité du pays et réagissent, à leur manière, à ce conflit. À travers onze histoires différentes, que chaque danseur transmet singulièrement, cette œuvre cherche à multiplier les points de vue, à empêcher le dogmatisme. Comme le rappelle l'une des danseuses, Laura Ardila qui représente une paysanne qui a perdu son fils, dont le mari s'est suicidé, et qui finit par s'unir à un groupe paramilitaire, « l'œuvre propose une réflexion sur la valeur de la vie qui est remise en cause dans le pays ». Que faire lorsque le nombre remplace l'être, lorsque s'efface l'idée d'humanité ? Sur scène, les différents regards proposés à travers ces corps en mouvement racontent les parcours d'hommes et de femmes aliénés, qui cherchent à survivre. La violence devient une option parmi d'autres, les corps se standardisent, tout comme les esprits, et transforment les êtres en simples pions des intérêts, des pouvoirs et des institutions. Chaque type de violences est métaphorisée et interagit sur scène : la violence physique d'abord, mais aussi la violence psychologique, la violence institutionnelle... Le mouvement des danseurs se transforme en un message «sublime ", qui nous saisit et nous dessaisit, car l'élévation ne va pas sans la descente qui la précède : «Quand le sublime vient à éclater où il faut, c'est comme la foudre : il disperse tout sur son passage et montre aussitôt la force [du danseur] dans sa plénitude $»^{1}$.

« 45.232.511 », mis en scène par Ana Milena Navarro 


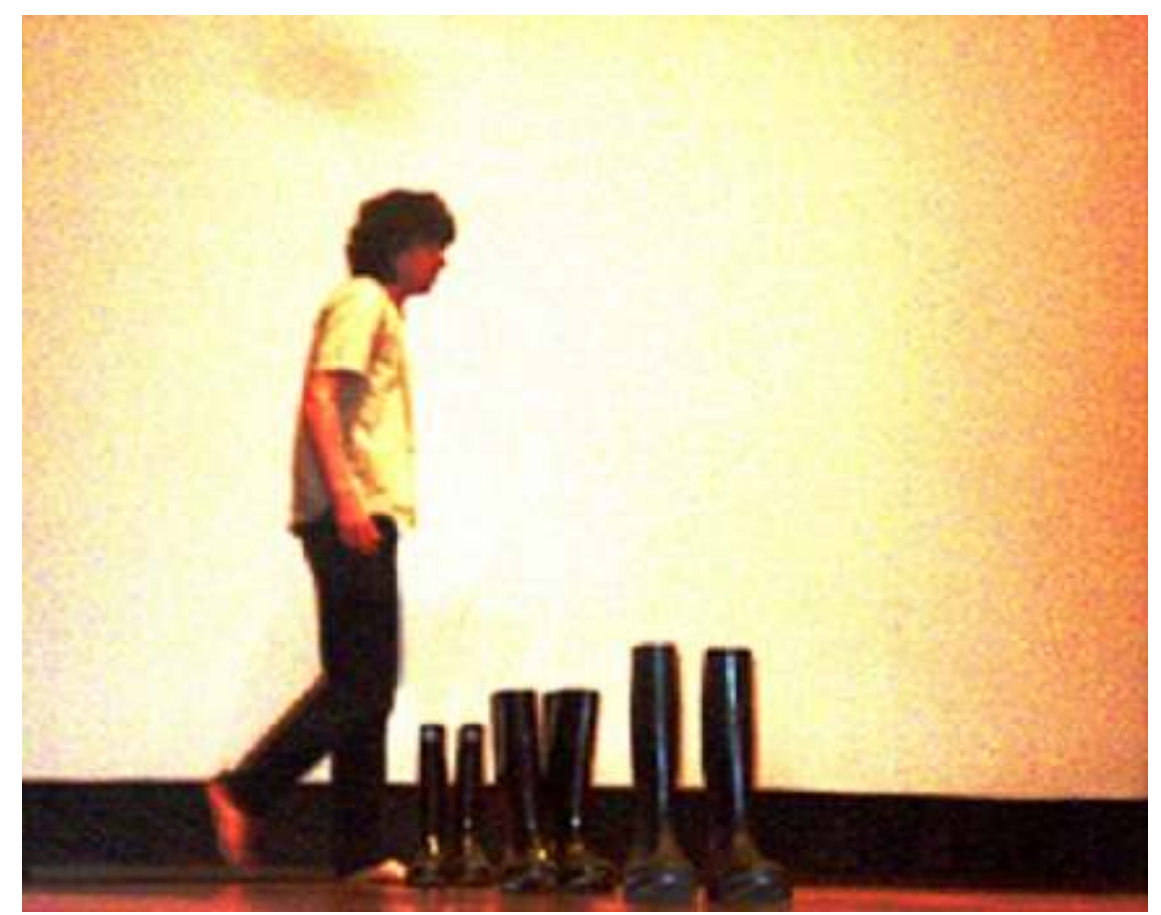

CRÉDIT : DR

Le spectateur est alors pris en porte-à-faux dans la contemplation de cette mer agitée. En effet, il est comme tiraillé entre différentes forces, différentes sensations et semble faire partie de cette création artistique. Celle-ci apparaît d'ailleurs comme un bon exemple de fonctionnement pour le pays: les danseurs dialoguent, passent par des moments conflictuels intenses, par des moments forts et harmonieux, tout comme dans la vie. Finalement, il s'agit de représenter non plus la violence, ni l'anonymat, mais l'engagement des citoyens, des Colombiens, afin de faire comprendre que les erreurs de chacun - en l'occurrence des danseurs - se répercutent sur l'ensemble de la société, que chaque décision, chaque geste, a une valeur performative.

4 «45. 232. 511 » se présente comme le parangon d'un art global, donc, d'un véritable moment collectif où nous nous sentons tous concernés : metteur en scène, interprètes et spectateurs. L'œuvre s'élève contre l'utilisation financière de la thématique de la violence, thématique qui fait vendre en Colombie et a pour vocation de redorer le blason, à travers le corps, d'une population particulièrement riche, sensible et positive, notamment sur le plan humain.

\section{NOTES}

1. Du sublime, Longin, I, 4 
INDEX

Mots-clés : Navarro (Ana Milena), 45.232.511, théâtre Jorge Eliécer Gaitán, Bogota 